\title{
Increasing Demand For IT Auditing Creates New Career Options For AIS/MIS/IT Students
}

Jeffrey W. Merhout, (Email: merhoujw@muohio.edu), Miami University Pauline E. Cothran, (Email: pauline.cothran@53.com), Bancorp, Cincinnati

\begin{abstract}
The demand to hire entry-level IT auditors is rising around the globe, mostly due to dramatic changes in laws and regulations. Employers in the United States are increasingly hiring MIS majors to fill IT audit positions, even graduates who have little or no formal education in auditing. MIS students and educators should have an awareness of the impact these new governance laws and regulations are having on IT operations. For students interested in IT audit careers, we describe the emerging field of IT auditing and discuss skills necessary for success in this profession. AIS/IT/MIS educators can help develop these skills, and can learn about some suggestions for doing so. IT executives and managers should also be aware of these shifting trends because they will affect their supply of qualified personnel and because many of the changes in laws and regulations will likely have an impact beyond their normal national scope.
\end{abstract}

\section{INTRODUCTION}

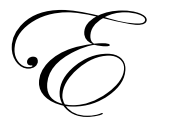

ducators in the information technology (IT), management information systems (MIS), and accounting information systems (AIS) disciplines may not be aware of the recent rapid increase in entry-level career opportunities in the IT audit profession in the United States for new college graduates. Despite the increasing demand for entry-level personnel, there remains a shortage of IT audit classes (not to mention curriculums) in business schools across the country. Thus, the primary purpose of this paper is to alert MIS/IT/AIS educators in business schools to the recent and ongoing growth of the IT audit profession and, perhaps more importantly, to the demand for MIS students as candidates for entry-level IT audit positions. Indeed, the demand is so great that employers are considering students who may have little or no formal auditing education.

One of the key reasons for this increased demand for information system (IS) auditing skills - the recent dramatic changes in the regulatory environment for U.S. public companies - may also compel some current IT professionals to understand how these regulations might affect their job responsibilities and to respond accordingly. Accordingly, we will briefly address the need for some IT personnel to expand their job scope to become cognizant of the requirement to document and assess IT risks and controls in order to help management comply with new financial disclosure regulations.

The first author of this paper was formerly a Certified Public Accountant (CPA) and is currently a faculty member in the Miami (Ohio) University School of Business MIS department, and also serves as the Academic Advocate (i.e., faculty advisor) for the University's student Information Systems Audit and Control Association (ISACA) chapter. This student chapter was recently founded because of the work and encouragement of members from the local professional ISACA chapter who ultimately want to leverage their opportunities to hire our graduates. This paper's second author is a recent graduate from this Miami's MIS program and a senior IT auditor with a large bank. The research for this paper thus benefits from insights gleaned from real-world education and career experiences in addition to numerous semi-structured interviews/discussions with members of the IT audit professional community. 
The next section of this paper describes IT auditing and discusses the key reasons for the increased demand for IT audit professionals. We then provide a general description of a typical IT auditor job. Thereafter we summarize the knowledge, skills, and abilities necessary for success in this profession. This discussion is in part supported by a compilation of an intensive content analysis of IT audit job advertisements posted on the Web by employers. We conclude with a discussion of how AIS/MIS educators can help students prepare for possible IT audit careers and note how these resource trends may affect IT managers. It is notable that the data/evidence for this paper comes from three sources: a literature review, insights from IT audit professionals, and analyses of IT audit job advertisements. Hence, this essay benefits from empirical support.

\section{INCREASING DEMAND FOR IT AUDITING}

To better conceptualize IT/IS auditing, one should have working understanding of IT governance, which is the process of effectively controlling an organization's IT resources to establish strategic information technology competencies and to comply with regulatory and contractual obligations (Hunton, Bryant \& Bagranoff, 2004; Luftman, Bullen, Liao, Nash, \& Neuman, 2004). One component of IT auditing consists of assessing IT security risks and implementing and/or monitoring controls for these risks, with the strategic goal of ensuring IT governance (Hunton et al., 2004). Gelinas, Sutton \& Fedorowicz (2004, p. 243) define risk as the "possibility that an event or action will cause an organization to fail to meet its objectives (or goals)." As an example, in this context, risk is related to the possibility that information systems will fail and/or be breached and cause the organization not to meet its objectives of effective information asset security and management.

IT governance is growing increasingly important for a multitude of reasons, including: a dramatic escalation in IT spending; the growing use of interactive Websites for e-commerce; increased terrorism and cybercrime that can affect information assets; and recent corporate scandals, such as Enron, Tyco International and Parmalat (an Italian dairy-food multinational) which have made corporate governance a top priority. In recent years there have been numerous reports of private data security breaches in the U.S. (e.g., 270,000 personal applicant data records at the University of Southern California; 40 million credit and debit card accounts at CardSystems Solutions; 26.5 million personal records of military personnel from the U.S. Department of Veterans Affairs), which could ultimately lead to identity theft and personal financial losses by consumers. As public concerns over identify theft continue to rise, lawmakers have already responded (e.g., California Online Privacy Protection Act of 2003; New York Information Security Breach and Notification Act of 2005; Japan's Personal Information Protection Law of 2005) and may soon enact even more laws (e.g., the Specter-Leahy Personal Data Privacy And Security Act, which was placed on the U.S. Senate Legislative Calendar in November 2005). These laws and regulations require organizations to enact specific measures to protect against schemes such as phishing, key logging, and packet sniffing that may be used to access personally identifiable (i.e., sensitive) data. This phenomenon certainly has potential implications on future corporate regulatory requirements, which of course, could lead to an additional need for IT auditors.

In addition to these factors, U.S. companies have an increased compliance requirements resulting from laws and regulations (all of which impact IT controls), such as the Federal Deposit Insurance Corporation Improvement Act of 1991 (FDICIA), the Health Insurance Portability and Accountability Act of 1996 (HIPAA), the Homeland Security Act of 2002, the Sarbanes-Oxley Act of 2002 (SOX), the Fair and Accurate Credit Transactions Act of 2003 (FACT), and auditing standards for CPA firms promulgated by the U.S. Public Company Oversight Board (PCAOB) (Gallegos, 2004; IT Governance Institute, 2004; Volonino and Robinson, 2004). Moreover, many of these regulations have an international reach. For example, Gattiker (2005, p. 23) notes that SOX and HIPPA "affect risk management in Europe as well" and that "European firms with NYSE listings are trying to cope with these regulatory demands and their deadlines."

While all of the above governmental regulations (and several others not mentioned in this paper) have resulted in pressure on organizations to ensure adequate controls over their IT assets and processes, the SarbanesOxley Act has perhaps been the impetus for the most dramatic increase in the need for more rigorous assessments and testing of IT controls, thereby significantly increasing the demand for more qualified IT audit personnel. Hoffman (2004) notes that the Big Four public accounting firms are facing a dearth of qualified IT audit professionals to assist their clients in doing controls documentation assessments mandated by Section 404 of SOX. Additionally, many 
companies are realizing their IT audit needs are too expansive to be met using only external auditors. In response to these requirements, they are adding an IT audit component to their internal audit departments. In some cases these companies have even quadrupled the number of IT audits they are performing, leading to an overwhelming demand for IT audit professionals (Needleman, 2006). While Sarbanes-Oxley's focus is on general internal control over financial reporting (to help alleviate corporate accountability problems like Enron and to restore investor confidence in capital markets), the processes used for financial reporting are nonetheless heavily reliant on information technology (IT Governance Institute, 2004). Accordingly, organizations must include IT controls in their mandated assessments before their executive officers can safely certify they are in compliance with this law on their financial statements.

Sarbanes-Oxley requires that each publicly traded corporation adopt and implement an appropriate internal control framework. The most frequently adopted framework for compliance with SOX is COSO, which was developed based on recommendations of the Committee of the Sponsoring Organizations of the Treadway Commission (IT Governance Institute, 2004). However, because COSO does not address the details of IT controls (Hunton et al., 2004; IT Governance Institute, 2004), the IT Governance Institute (ITGI) developed a framework to integrate internal controls for information technology. This framework is called Control Objectives for Information and related Technology (COBIT $\left.{ }^{\circledR}\right)$. According to a survey of international firms commissioned by the ITGI, since COBIT is compatible with COSO, a large percentage of its adopters were very satisfied using it as an IT controls framework (Global Communiqué, 2004).

However, while there are suitable control frameworks available to deal with Sarbanes-Oxley, the Act "has [nonetheless] fundamentally changed the business and regulatory environment" so much that IT professionals, particularly those in executive positions such as CIOs must become "well versed in internal control theory and practice" (IT Governance Institute, 2004, p. 12). This is particularly important given the requirement that a corporation's executive and financial officers (many of whom are not likely to be extremely knowledgeable about IT) must certify that their financial reporting systems have adequate controls in place. These certifying officers undoubtedly will rely heavily on their IT executives to ensure that the necessary controls are indeed in place and functioning adequately. These IT executives will, in turn, rely on the rank-and-file IT workers to comply with the details of their information technology related controls assessment and testing (both from within the IT department and from the organization's internal IT audit staff). These control assessment details include: mapping the information systems that support the financial reporting process; identifying risks in these systems; designing and implementing internal controls to mitigate these risks; and documenting, testing and monitoring these controls (IT Governance Institute, 2004). Thus, IT executives and managers should also be aware of this continuing regulatory requirement because it will require an adequate supply of qualified IT personnel who are knowledgeable in the concepts presented in this paper.

\section{GENERAL IT AUDITOR JOB DESCRIPTION}

IT auditors provide a variety of services to IT departments including creating awareness of regulatory requirements, providing continuous monitoring of the IT environment, conducting audits to identify risks within the environment, and analyzing the controls that are expected to be in place to mitigate these risks. IT audits usually address technologies or processes within the application, infrastructure, or governance layers of the IT environment. During a typical IT audit, an IT auditor will initially perform an assessment of the inherent risks (risks in absence of controls) related to the technology or process being audited and then determine how each risk may impact the business, as well as the likelihood that each risk will occur. The estimated level of risk (also know as risk rating) will determine the extent of the testing around each risk. The auditor will then work with IT management to identify the controls that are in place to mitigate those risks.

From this perspective controls may be classified as one of three types: preventative, detective or corrective. For each risk, the IT auditor will ensure that an appropriate mix of the three types of controls are in place to mitigate the risk, as well as evaluate whether they are functioning adequately. Based upon this evaluation, IT auditors determine the level of residual risk remaining in the environment. For example, sales figures on financial statements are the summarized results of potentially millions of individual transactions, each of which is at risk of being 
misstated because of inaccuracies in the transaction capturing process. Thus applications, such as sales and marketing information systems, must have effective controls in place to minimize the risks of misstatements. Input controls are one category of such controls, and are intended to ensure that only valid transactions are recorded and are recorded in an accurate and complete manner (Hall \& Singleton, 2005).

An example of an input control for sales transactions is a limit or range check in the interface, which ensures that values, such as prices, do not exceed some upper or lower limit. The purpose is to detect errors (either intentional or unintentional) in input, output and processing functions; e.g., a sales representative trying to exceed a maximum discount percentage when negotiating prices with customers or keystroke errors that might accidentally shift a decimal point a place or two. An example of auditing such an input control is to thoroughly understand the logic of the programming used in the application to ensure that the controls work as intended and to design test data that subject the application to a variety of undesirable conditions that should be detected by these controls (Hall, 2002). This is an illustration of a control that can be more broadly categorized as an application control because it is related to a specific transaction processing application. Another broad category of controls is referred to as general IT controls, which usually address the following areas: logical security, physical security, change management, support, and disaster recovery planning. A related IT control applicable to this example is controlled "access to programs and data" where only authorized persons should have access to applications such the sales transaction interface (IT Governance Institute, 2004, p. 20).

Documenting and testing these IT controls is invariably time-consuming, especially for those organizations not in industries that are used to heavy regulation and compliance. Accordingly, these activities will likely require many hours of IT personnel time. As auditors must act independently, an internal auditor will not be able to significantly rely on work performed by an external auditor, and vice-versa; this often results in IT personnel involvement in concurrent audits. In other words, some of these audits may overlap and require time-consuming procedures to be repeated, especially if adequate documentation is not in place. Moreover, Sarbanes-Oxley requires a company's outside auditing firm to attest that the company's management has made an adequate assessment of internal controls over its financial reporting processes, which "are [inherently] driven by IT systems" (IT Governance Institute, 2004, p. 19). As noted by Hoffman (2004, p. 16), [u]nlike Y2k work, Sarbanes-Oxley compliance efforts are expected to be an ongoing exercise in which companies will have to document their internal controls on a quarterly basis and have them certified by auditors annually." In short, many new qualified entry-level IT auditors (both external and internal to the organization) will be needed to document and assess the IT components of these controls in order to be in compliance with SOX requirements.

\section{SKILLS REQUIRED FOR EFFECTIVE IT AUDITING}

We have discussed reasons for the increasing demand for new IT auditors and described a typical auditor's job responsibilities; however, we have not explicitly outlined the skills that can be reasonably expected of a candidate for an entry-level IT audit position. The material for this section was synthesized from both the literature and from actual conversations with knowledgeable persons: managers hiring information systems auditors and some recently hired entry-level IT auditors. It is noteworthy that, in many instances, the comments from these managers and new hires are very consistent with the skills noted in the literature we have reviewed.

According to Hunton et al. (2004), an IT auditor usually holds a bachelor's degree with a major in MIS, computer science, and/or accounting, but could conceivably have a variety of majors. Hunton et al. (p. 8) add that, although knowledge of technical topics (e.g., operating systems, network security, e-commerce) is "highly desirable, it's probably most important that an individual planning a career in IT audit just genuinely 'like' computers and technology." This notion was seemingly confirmed by one insurance company's IT audit hiring manager who was recruiting entry-level IT auditors from our business school. Unlike many of the hiring contacts we interviewed, this manager was not overly concerned with a potential candidate's major - the student simply had to have a good aptitude for technology, a high GPA, and strong interpersonal skills.

Hunton et al. further note that " [w] hile technical skills are important to an IT auditor, general communication and business skills probably matter even more" (p. 8). Under desirable personal and business skills, these authors 
discuss interpersonal and teamwork skills because IT auditors need to work with other auditors (both financial and IT auditors, and both internal and external auditors) and gain acceptance and support from the client (or audited group). In addition, IT auditors must possess an understanding of business processes because the information systems being audited support the business functions of an organization. Accordingly, knowledge of accounting (or an accounting major or minor) is a plus, primarily because accounting focuses on processes and because most accountants have studied auditing. Other useful skills (or co-majors) include marketing (in order to sell services and suggestions about controls to clients) and decision sciences (to be able to use statistical tools to analyze the sheer volumes of data that are involved in financial reporting processes). Finance is also a pertinent co-major for those IT audit positions in the various financial service industries.

From our research and experiences, we have noted additional skills and qualities that will help ensure success in the IT audit profession. Perhaps foremost is that an auditor must be the consummate professional. For example, auditors need to attend to the important nuances of phone and meeting etiquette (e.g., being on time, using appropriate language, etc.) and be courteous to those responding to audit requests (e.g., give them sufficient lead time). Auditors also need excellent communication and reasoning skills in order to create effective audit plans and to express findings, concerns, and recommendations to upper management, both in writing and during meetings. In addition, auditors must be able to work effectively with people at all levels of an organization, including being an effective listener and sometimes even negotiating with clients. In short, IT auditors must continuously work to portray the aura of a professional, which is one of those important interpersonal skills that can be called upon to "overcome the negative bias towards auditors of people whose work is under their scrutiny" (Hunton et al., 2004, p. 8). Finally an IT auditor needs to understand the concept of risk as it is related to IT and acknowledge that auditors (even internal auditors) have to be independent (because management is actually responsible for controls over assets). This independence must manifest itself both in form and appearance: auditors must always give the appearance of being independent, such as using language in oral conversations that implies management responsibility; moreover, auditors need to formally express this independence by stating unequivocally (in writing) that management is ultimately responsible for controlling its assets.

The relative importance of some of these entry-level skills is predicated on a given position's education requirements, which appear to vary slightly from public accounting (i.e., CPA firms) to industry (i.e., internal auditing). In our metropolitan area and region of the country, it appears that public accounting firms have a fairly strong preference for entry-level IT auditors who have an accounting degree with MIS or IT as a double major or minor (partly in response to more stringent professional certifications required for CPA firms by the PCAOB). On the other hand, companies that are not accounting firms appear to have broader hiring guidelines and will hire business graduates without an accounting degree, but rather with an MIS major or perhaps with another business major (such as finance) and an MIS minor or concentration. These companies, after all, are charged with documenting, assessing and testing IT controls and need to hire graduates with information technology and systems acumen, which does not necessarily require a detailed understanding of accounting and auditing at the IT control level. Rather, these professionals need a detailed understanding of IT and of its associated risks and security issues.

In order to supplement our literature research and anecdotal evidence, we conducted a preliminary study of IT audit jobs (or some variation of this key word phrase) advertised in several major U.S. cities via the Internet (e.g., Monstor.com, Careerbuilder.com, New York Times Online). We found that almost no entry-level jobs were advertised in this manner, which lead us to conclude that the firms needing entry-level IT auditors were recruiting directly on college campuses (which is definitely the case at Miami University). However, we believed that IT audit job advertisements requiring pertinent work experience would be informative in the types of skills required to advance in this profession. Similar to studies by Wade \& Parent (2002 - a "job-content analysis" on Webmaster wanted classified advertisements) and Prabhakar, Litecky, \& Arnett (2005), we examined 68 job postings from September 2004 through March 2005 and are currently examining another 595 job postings from October 2005 through April 2006. Some of the key skills we found in the ads highlighted include "good communication skills" (60\% of the advertisements in both time frames specifically mentioned this), "experience with controls" (34\% of 2004-05 ads), "risk assessment experience" (10\% of 2004-05 ads), and "teamwork," "being a self starter," and having "analytical and problem solving skills" (all three were mentioned in 7\% of the 2004-05 advertisements, although not necessarily in the same postings). 
In summary, we have developed the following table that highlights the essential IT audit skills and knowledge we have identified in our research and experiences:

Key IT Audit Skills And Knowledge Summary Table

\begin{tabular}{|l|}
\hline Aptitude for and "like" computers and information technology \\
\hline Understanding business processes \\
\hline Oral and written communication skills \\
\hline Accounting, Marketing, Decision sciences/statistics, Finance \\
\hline Professionalism \\
\hline People skills: teamwork, listening, negotiating \\
\hline Reasoning, analytical and problem solving \\
\hline Risk assessments \\
\hline Controls \\
\hline Independence \\
\hline
\end{tabular}

\section{CHANGES NEEDED IN AIS/MIS/IT CURRICULUMS}

Singleton (2003) calls for more research and education on the ramifications of SOX on the IT audit profession from an accounting curriculum perspective. However, as suggested in our paper, the impact of SOX is similar for the MIS curriculum, and MIS educators would provide a service to their students by creating an awareness of related topics, such as IT governance, Sarbanes-Oxley, systems security, risks and controls, COBIT, IT auditing, and ISACA, which is an international organization dedicated to the IT audit profession, and of some of the key skills necessary for success. Moreover, we should call to the attention of undergraduate MIS majors the possible career opportunities in IT auditing. Fortunately, ISACA provides a Model Curriculum on their Website (at no charge) for those institutions desiring to add courses and content on these topics (ISACA, 2004).

This Model Curriculum is broken down into seven content domains - Audit Process; Management, Planning and Organization of IS; Technical Infrastructure and Operational Practices; Protection of Information Assets; Disaster Recovery and Business Continuity; Business Application System Development, Acquisition, Implementation and Maintenance; Business Process Evaluation and Risk Management - which map to the Certified Information Systems Auditor ${ }^{\circledR}\left(\right.$ CISA $\left.{ }^{\circledR}\right)$ examination content areas. In addition to incorporating these suggestions into MIS curriculums, educators can contact the ISACA professional chapters in their areas to inquire into the possibility of creating a student ISACA organization at their school that will be affiliated with a local ISACA chapter (see www.isaca.org). This affiliation can manifest itself in varying ways, but one of the most powerful ways to draw attention to MIS majors is having professionals from these local chapters come to campus to talk about careers in IT auditing.

Another way to draw attention to the IT audit profession is for AIS/MIS/IT educators to discuss some of the professional credentials and certifications that are available in the profession (similar to how the accounting discipline continuously reinforces the importance of the CPA designation for their majors). Ryan and Schou (2004, p.29) note, "the number of individuals seeking certification or academic credentials in the information security area is rising dramatically, much faster than the general rise in educational achievements for the general populace." According to Hunton et al. (2004), perhaps the most prestigious international credential available to entry-level IT auditors is the CISA designation offered by ISACA (see www.isaca.org). Ryan \& Schou $(2004$, p. 29) in reference to the CISA, remark that "a certification last[ing] for three decades in the information era is a testament to the value associated with the certification from both the employers' and the employees' perspectives." Mansour (2005, p. 22) adds, "[t]here has been a dramatic increase in the number of CISA-certified practitioners [in the U.K.]" - this is thus one indication of the global appeal of this certification.

The CISA certification requires: the successful completion of the CISA examination; five years of professional experience in IS auditing, control or security (some of which can be waived, such as by earning a college degree); adhering to a code of professional ethics; adhering to a code of auditing standards; and maintenance of skills 
through continuing professional education. The different weights assigned to the content areas of the CISA exam supports our theory that IT skills are more important than general knowledge of auditing. The exam is divided into seven content areas, each weighted according to its importance. The sections receiving the highest weights are "Protection of Information Assets" (representing 25\% of the exam) and "Business Application System Development, Acquisition, Implementation and Maintenance" (16\% of the exam) while the "IS Audit Process" area is only 10\%. Many of these IT subject areas mentioned here are often included in MIS curriculums, giving entry-level IT auditors with a MIS or related degree an advantage when preparing for this certification. Moreover, we have found that developing just one new course (which we call "Information Risk Management, Security \& IT Audit" at Miami University) can provide a solid foundation for continued study towards this examination. More, based on conversations with recruiters, this course also gives our students more credentials for seeking the lucrative entry-level positions available in IT audit.

Another potential designation also offered by ISACA is the Certified Information Security Manager (CISM), which is intended for experienced security managers. Other pertinent certifications noted by Hunton et al. include Certified Fraud Examiner (CFE), Certified Information Technology Professional (CITP), and Certified Internal Auditor (CIA). There are numerous other possible certifications available, although these tend to be directed more towards information security professionals rather than IT auditors (but could be pertinent in the long-term careers of MIS majors who go to work in IT audit directly out of college). According to Whitman and Mattord (2005), some of these include: Certified Information Systems Security Professional (CISSP); Systems Security Certified Practitioner (SSCP); Global Information Assurance Certification (GIAC), and Certified Information Forensics Investigator (CIFI). The plethora of certifications available (many from vendor neutral organizations) is an indication that this profession strives for high ideals in terms of service to its stakeholders and to the development of its workforce. Moreover, we found in our content analysis of IT audit job advertisements that 69\% of the ads in the 2004-05 time frame noted certifications such as CISA, CISM, CISSP and/or CFE as a "must" or at least a "plus." These findings in the U.S. mirror Mansour's (2004) argument that certification is becoming more important over the past few years in the U.K., which suggests that this is an international phenomenon.

\section{CONCLUSION}

IT audit is also an excellent career choice for new graduates (from MIS or related programs) whose ultimate goal may be a career in IT, but who are unsure where their interests lie or perhaps lack the specific technical skills to jump directly into a meaningful IT role after graduation. All areas within IT are subject to audit, giving IT auditors an overview of the entire IT environment (e.g., infrastructure). This provides a multitude of opportunities for IT auditors to transition into the formal IT function if they so desire. At the bank employing this paper's second author, three members of the IT audit department, each at different levels within the department (the director of IT audit, an IT audit manager, and an IT audit senior) have all taken positions within the IT department within the last year or so. Of the three, two took IT governance-related positions; the IT Audit Director became the head of Systems and Operations Risk Management Services, reporting directly to the Chief Information Officer, and responsible for information security, IT risk management, disaster recovery, and IT governance. The IT audit manager took on a role as the liaison between audit and IT. The third person, the IT audit senior, transferred into a technical role as a quantitative analyst within the company's IT business intelligence area.

In addition to the IT audit function acting as a stepping stone into IT, the overall demand for IT audit services and professionals is increasing, both in the U.S. (Gallegos, 2003) and internationally (Dodds, 2005; Sadarangani, 2005), making it an excellent choice for those interested in information technology, but with few or no advanced technical skills. For example, a July, 2005 search for "IT or information technology or information systems and auditor" on Monster.com revealed over 900 jobs available across the U.S. that were posted in just the previous 30 days. A similar search in May, 2006 revealed over 1000 available jobs. Indeed the demand for IT audit professionals exceeds the supply (Gallegos, 2003; Needleman, 2006; Rosenthal-Sabroux, 2006), and thus many companies are willing to hire MIS students straight out of college with little accounting and auditing education and train them to be IT auditors. 
Consequently, MIS/IT/AIS educators should be aware of this emerging trend and act accordingly for the best interests of their students; for example, we encourage these educators to use ISACA's resources to the benefit of their stakeholders. IT managers should also be cognizant of the trends we have outlined because the changes will affect the supply of qualified personnel and possibly impact the scope of security and privacy laws and regulations that affect their operations.

Note: An earlier version of parts of this paper was presented at the 2005 Information Resources Management Association International Conference in San Diego, CA.

\section{REFERENCES}

1. Dodds, R. (2005), Global Perspectives: The Changing Role of the IT Auditor - An Oceania Perspective. Information Systems Control Journal, 2005(3), 24.

2. ITGI Surveys Marketplace. (2004). Global Communiqué, Information Systems Audit and Control Association Newsletter, 2004(6), 1, 5, 7.

3. Gallegos, F. (2003). IT Auditor Careers: IT Governance Provides New Roles and Opportunities. Information Systems Control Journal, 2003(3), 40-43.

4. Gallegos, F. (2004). Strategy Issues: Sarbanes-Oxley Is Only Part of the Solution. Information Systems Control Journal, 2004(1), 11-12.

5. Gattiker, U.E. (2005). Global Perspectives: The Changing Role of the IT Auditor - A European Perspective. Information Systems Control Journal, 2005(3), 22-23.

6. Gelinas, U.J., Sutton, S.G., and Fedorowicz, J. (2004). Business Processes and Information Technology. Mason, OH: Thomson South-Western.

7. Hall, J.A. (2002). Information Systems Auditing and Assurance. Mason, OH: South-Western College Publishing.

8. Hall, J.A. and Singleton, T. (2005). Information Technology Auditing and Assurance. $2^{\text {nd }}$ ed., Mason, OH: South-Western College Publishing.

9. Hoffman, T. (2004). IT Auditors Coveted, Hard to Find. Computerworld, 38(18), 1, 16.

10. Hunton, J.E., Bryant, S.M., and Bagranoff, N.A. (2004). Core Concepts of Information Technology Auditing. Hoboken, NJ: John Wiley \& Sons, Inc.

11. Information Systems Audit and Control Association (ISACA) (2004). ISACA Model Curriculum for IS Audit and Control. Retrieved December 29, 2004 from www.isaca.org.

12. IT Governance Institute (2004). IT Control Objectives for Sarbanes-Oxley: The Importance of IT in the Design, Implementation and Sustainability of Internal Control over Disclosure and Financial Reporting. Retrieved July 16, 2004 from www.itgi.org.

13. Luftman, J.N., Bullen, C.V., Liao, D., Nash, E., and Neuman, C. (2004). Managing the Information Technology Resource: Leadership in the Information Age. $1^{\mathrm{st}}$ Ed., Upper Saddle River, NJ: Pearson Education, Inc.

14. Mansour, C. (2005). Global Perspectives: The Changing Role of the IT Auditor - A UK Perspective. Information Systems Control Journal, 2005(3), 22.

15. Merhout, J.W. and Cothran, P.E. (2005), IT Auditing: A Possible Career for MIS Majors, in M. KhosrowPour (ed.), Managing Modern Organizations with Information Technology, pp. 399-401. Proceedings of the 2005 Information Resources Management Association International Conference, San Diego, CA, USA.

16. Needleman, S.E. (2006). Info-Systems Watchdogs See More Job Options, Pay Gains. The Wall Street Journal Executive Career Site. Retrieved May 30, 2006 from www.careerjournal.com/salaryhiring/industries/computers/index.html.

17. Prabhakar, B., Litecky, C.R., and Arnett, K. (2005). IT Skills in a Tough Job Market. Communications of the ACM, 48(10), 91-94.

18. Rosenthal-Sabroux, C. (2006). Global Perspectives: The Current State of IT Audit Education - A French Perspective. Information Systems Control Journal, 2006(2), 17. 
19. Ryan, J.J.C.H. and Schou, C.D. (2004), On Security Education, Training and Certifications. Information Systems Control Journal, 2004(6), 27-30.

20. Sadarangani, P. (2005), Global Perspectives: The Changing Role of the IT Auditor - An Asia-Pacific Perspective. Information Systems Control Journal, 2005(3), 23-24.

21. Singleton, T. (2003). The Ramifications of Sarbanes-Oxley. Information Systems Control Journal, 2003(3), 11-16.

22. Volonino, L. and Robinson, S.R. (2004). Principles and Practice of Information Security: Protecting Computers from Hackers and Lawyers. Upper Saddle River, NJ: Pearson Education, Inc.

23. Wade, M.R. and Parent, M. (2002), Relationships Between Job Skills and Performance: A Study of Webmasters. Journal of Management Information Systems, 18(3), 71-96.

24. Whitman, M.E. and Mattord, H.J. (2005). Principles of Information Security, $2^{\text {nd }}$ ed., Boston: Thomson Course Technology.

\section{NOTES}




\section{NOTES}

